\title{
Balloon-Expandable Stent Treatment of Experimental Coarctation of the Aorta: Early Hemodynamic and Pathological Evaluation
}

\author{
ROBERT H. BEEKMAN, M.D., F.A.C.C., ${ }^{*}$ DAVID W.M. MULLER, M.B.B.S., ${ }^{* *}$ \\ PAUL I. REYNOLDS, M.D., † CATHERINE MOOREHEAD, B.S., \\ KATHLEEN HEIDELBERGER, M.D. $\ddagger$ and FLAVIAN M. LUPINETTI, M.D.*** \\ From the Division of Pediatric Cardiology, *Departments of *Pediatrics, **Medicine, ${ }^{* * *}$ Thoracic Surgery, + Anesthesiology, \\ and $¥$ Pathology, C.S. Mott Children’s Hospital, The University of Michigan, Ann Arbor, Michigan
}

\begin{abstract}
The present study was intended to evaluate the acute and short-term hemodynamic, angiographic, and pathological response to balloon-expandable stent treatment of experimental coarctation of the aorta. A discrete thoracic coarctation was surgically created in six mongrel dogs (two adults, four puppies). Two months postoperatively all six dogs $(8.9-30 \mathrm{~kg})$ underwent left heart catheterization and coarctation stenting performed through a femoral artery cutdown. A Palmaz PS-30 stent was advanced to the coarctation through a lOFrench sheath, and expanded with an angioplasty balloon chosen to equal the diameter of the proximal aorta $(9-12 \mathrm{~mm})$. Stent implantation was successful in each dog. The systolic pressure gradient decreased from $26.3 \pm 9.1 \mathrm{mmHg}$ (mean $\pm S E$ ) to $0.5 \pm 0.5 \mathrm{mmHg}$ $(P=0.04)$, and the coarctation diameter improved from $50 \pm 6 \%$ to $82 \pm 6 \%$ of the diameter of the proximal descending aorta $(P<0.01)$. Follow-up catheterization 4-7 weeks after stenting documented no stent migration, early restenosis, thrombosis, obstruction of arterial side branches, or aneurysm formation. Pathological evaluation of the explanted segments of stented aorta documented that by 6-7 weeks the stents are covered by a neointima composed of intimal proliferation and fibrosis with an endothelial cell surface. These data suggest that balloon-expandable stainless steel stents provide excellent acute and short-term relief of coarctation in this experimental model. Larger and longerterm studies are needed to better assess the incidence of restenosis or aneurysm formation following stenting of coarctation of the aorta. (J Interven Cardiol 1993; 6:113-123)
\end{abstract}

\section{Introduction}

Conventional therapy for coarctation, either surgical repair or balloon angioplasty, may yield unsatisfactory results in some patients due to residual or recurrent stenosis and/or late aneurysm formation. ${ }^{1-10} \mathrm{~A}$ balloon-expandable stainless

Supported in part by American Heart Association of Michigan Grant \#901CG110.

Address for reprints: Robert H. Beekman, M.D., Division of Pediatric Cardiology, Box 0204, F1310, C.S. Mott Children's Hospital. Ann Arbor, MI 48109. Fax: (313) 936-9470.

Submitted for publication October 15, 1992; accepted with revisions January 14, 1993; revisions returned January 25, 1993. steel stent (serving as an endovascular prosthesis to support the aortic wall after dilation) offers theoretical advantages over current therapies. A stent will buttress the aortic wall after dilation, thereby preventing the elastic recoil which is often responsible for an unsuccessful balloon angioplasty procedure. Further, by tacking intimal flaps against the vessel wall, ${ }^{11}$ stent support may diminish the likelihood of late aneurysm formation. The purpose of the present investigation was to evaluate the effectiveness of a balloon-expandable stainless steel stent (the Palmaz PS30 stent Johnson \& Johnson Interventional Systems, Warren, NJ, USA) in an experimental model of coarctation of the aorta. Specifically, we sought to determine if the stent can provide acute hemo- 
dynamic and angiographic relief of experimental coarctation, without early restenosis, thrombosis, aneurysm formation, or obstruction to arterial side branches. Finally, the short-term gross and microscopic tissue response to stent treatment was evaluated.

\section{Methods}

A discrete thoracic coarctation of the aorta was surgically created in six mongrel dogs (two adults and four puppies) through a left lateral thoracotomy performed under general anesthesia. The aorta was clamped proximally and distally beyond the left subclavian artery, and an incision was made across $50 \%$ of the diameter of the aorta. The resulting $V$-shaped defect was closed with a continuous suture of 5-0 polypropylene. No tissue was resected. Eight to 10 weeks after creation of the coarctation, all six dogs $(8.9-30 \mathrm{~kg})$ underwent left heart catheterization and coarctation stenting under thiamylal sodium anesthesia. Arterial access was achieved by right femoral artery cutdown and systemic heparin ( 100 units $/ \mathrm{kg}$ ) was administered. The coarctation pressure gradient was measured by catheter withdrawal from ascending to descending aorta, after which an ascending aortogram was filmed in the left anterior oblique projection. A Palmaz PS30 stainless steel stent $(3.4 \times 30 \mathrm{~mm})$ was mounted on an angioplasty balloon whose diameter was chosen to equal the diameter of the normal aorta immediately beyond the left subclavian artery (9-12 $\mathrm{mm}$ ). The stent was advanced through a 10 French sheath (Cook Inc., Bloomington, IN, USA) to the site of coarctation. The sheath was withdrawn slightly and contrast was injected through the side arm to assure that the stent was properly centered on the coarctation. The angioplasty balloon was then inflated by hand, and the stent dilated until the waist created by the coarctation on the stent either resolved or markedly improved. Balloon inflation pressures were not measured during the procedure, and no balloon ruptures occurred. After stenting. the angioplasty catheter was withdrawn and a pigtail catheter was advanced to the ascending aorta over a 0.35 in. exchange guide- wire. A repeat aortogram was filmed, after which pressures were again recorded in the ascending and descending aorta. The sheath was removed from the femoral artery, and the arteriotomy was repaired.

All six dogs recovered well and received no chronic anticoagulant or antiplatelet agents. One animal died an anesthetic death during an unrelated procedure 6 weeks after stenting. In this animal (whose stent was widely patent) followup aortic diameter measurements were obtained from postmortem angiography of the specimen, but late hemodynamic data were not obtained. In the remaining five dogs, a follow-up left heart catheterization was performed 4-7 weeks following stenting. The residual pressure gradient was measured prior to angiography by catheter withdrawal across the stented coarctation site, and an aortogram was filmed in the left anterior oblique projection. The animals were then sacrificed and the stented segment of aorta removed. Gross examination of all six specimens was performed to determine the extent of neointima coverage, patency of arterial side branches, and to detect evidence of thrombosis or aneurysm formation. The specimens were then fixed for microscopic evaluation.

Data Analysis. All angiographic diameters were measured by caliper from the left anterior oblique aortogram. The coarctation diameters were expressed as a ratio of the narrowest diameter over the diameter of the normal aorta proximal to the coarctation. Data are presented as mean \pm one standard error of the mean. Measures obtained before stenting, after stenting, and at follow-up are compared using a repeated measures analysis of variance. Pairwise comparisons are performed using the Scheffe test, with a $P$ value of $<\mathbf{0 . 0 5}$ required as evidence of a significant effect. The protocol was approved by the University of Michigan Committee on the Use and Care of Animals.

\section{Results}

Hemodynamic Data. Prior to stenting, a wide range of coarctation severity was documented, 


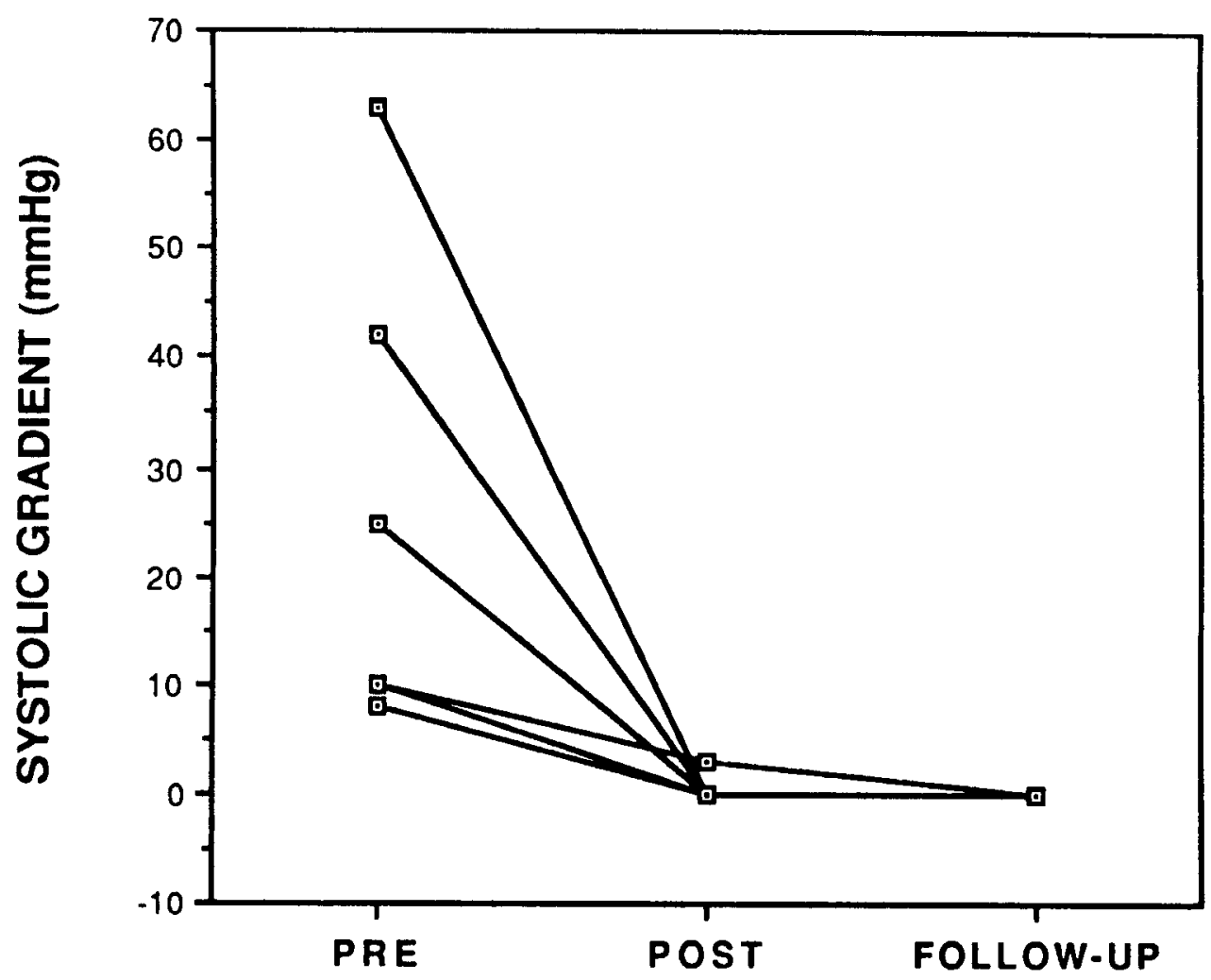

Figure 1. Systolic pressure gradient across the coarctation site before and immediately after stenting, and at 4-7 week follow-up study.

with peak-to-peak systolic pressure gradients ranging from $8 \mathrm{mmHg}$ to $63 \mathrm{mmHg}$. The stenting procedure provided acute relief of stenosis in all animals (Fig. 1). The systolic gradient decreased after stenting from $26.3 \pm 9.1 \mathrm{mmHg}$ to $0.5 \pm$ $0.5 \mathrm{mmHg}(\mathrm{P}<0.05)$. At follow-up catheterization 4-7 weeks after stenting, there was no residual systolic pressure gradient present in any animal. Systolic pressure in the ascending aorta was $185 \pm 22 \mathrm{mmHg}$ immediately prior to stenting, $176 \pm 10 \mathrm{mmHg}$ immediately after stenting, and $170 \pm 11 \mathrm{mmHg}$ at follow-up ( $\mathrm{P}=\mathrm{NS}$ for all pairwise comparisons).

Angiographic Data. The coarctation stenosis diameter, normalized as a percent of the proximal aortic diameter, increased in all animals after the stenting procedure (Figs. 2 and 3). The coarctation diameter increased acutely from $50 \pm 6 \%$ to $82 \pm 6 \%$ of the diameter of the proximal aorta $(\mathrm{P}<0.01)$. There was no evidence of restenosis at follow-up 4-7 weeks later, as the coarctation diameters had not changed $(87 \pm 5 \%)$. All stents were widely patent and there was no evidence of stent movement or migration, thrombosis or aneurysm formation at the follow-up angiographic study. The intercostal arteries traversed by the stent remained angiographically patent, both immediately after stenting and at the followup study (Fig. 4). Due to the location of the coarctation, the stent did not cross the origin of the left subclavian artery in any animal.

In two animals, the poststenotic descending aorta was noted to be substantially wider than the stent diameter immediately after stent implantation. In one animal, this size discrepancy was exaggerated by suboptimal distal positioning of the stent relative to the coarctation. In both animals, the 6-week follow-up angiogram documented that the poststenotic aorta had remodeled to equal the stent diameter (Fig. 5). Aortic remodeling occurred without angiographic or pathological evidence of thrombosis or restenosis. 


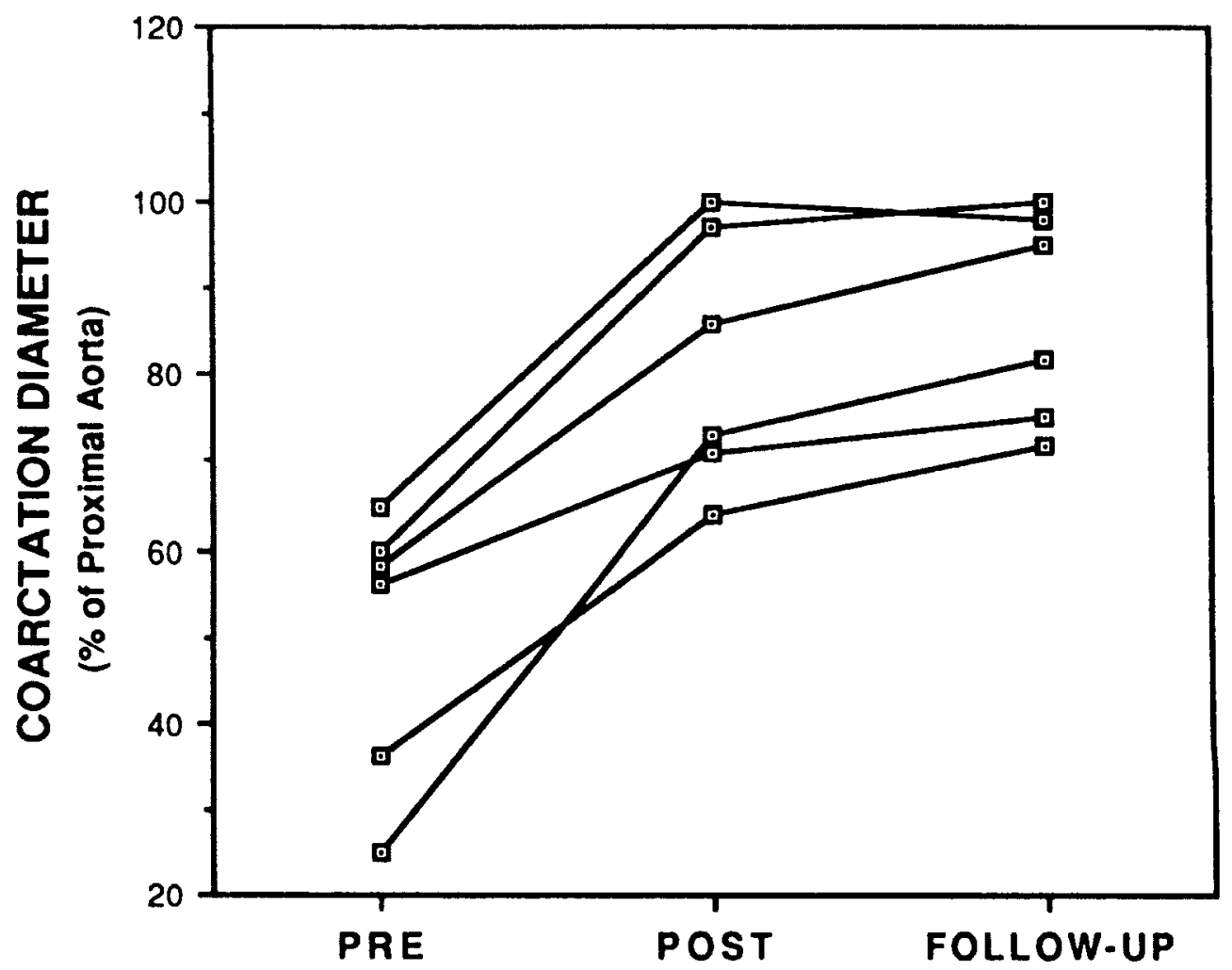

Figure 2. Coarctation diameter (as percent of proximal aorta diameter) before and immediately after stenting, and at $4-7$ week follow-up study.

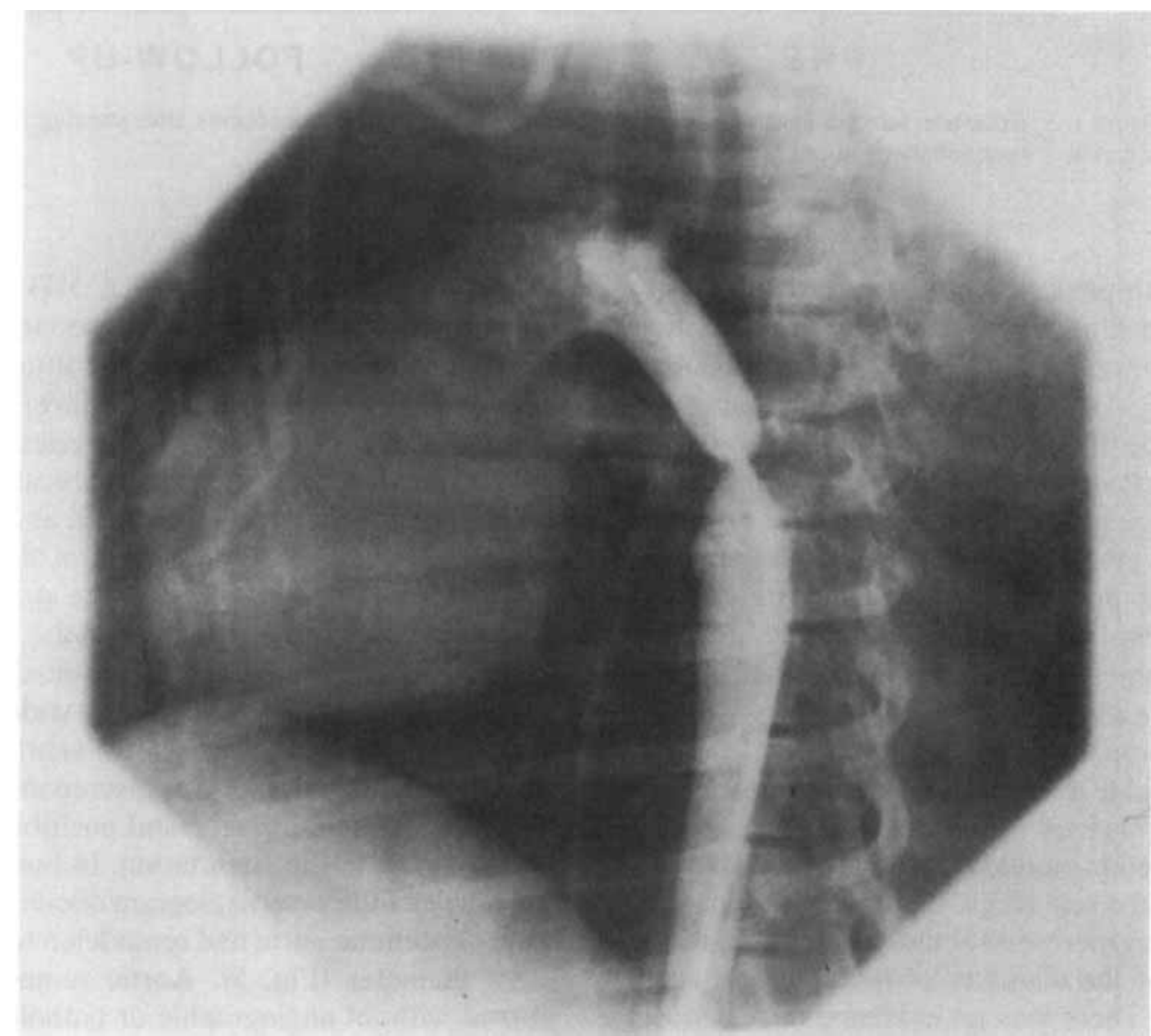

Figure 3a. Aortogram (left anterior oblique projection) showing a discrete coarctation in a $9.1-\mathrm{kg}$ puppy. The pressure gradient was $63 \mathrm{mmHg}$. 

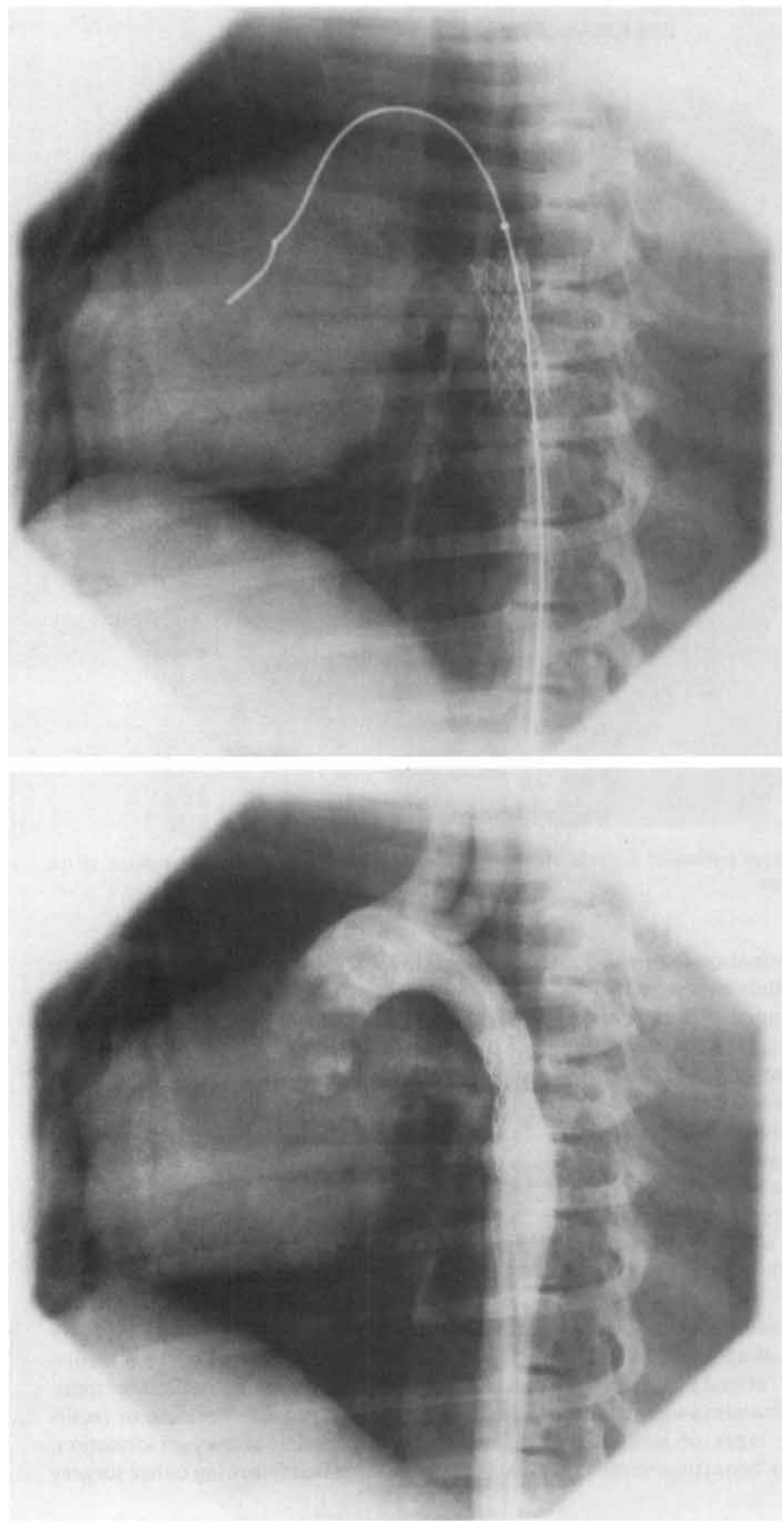

Figure 3b. A Palmaz balloon-expandable stent was dilated with a 9-mm balloon.

Figure 3c. Repeat aortogram demonstrating improvement in the coarctation (this is the most severe residual stenosis observed in the entire study). There was no residual pressure gradient present. 


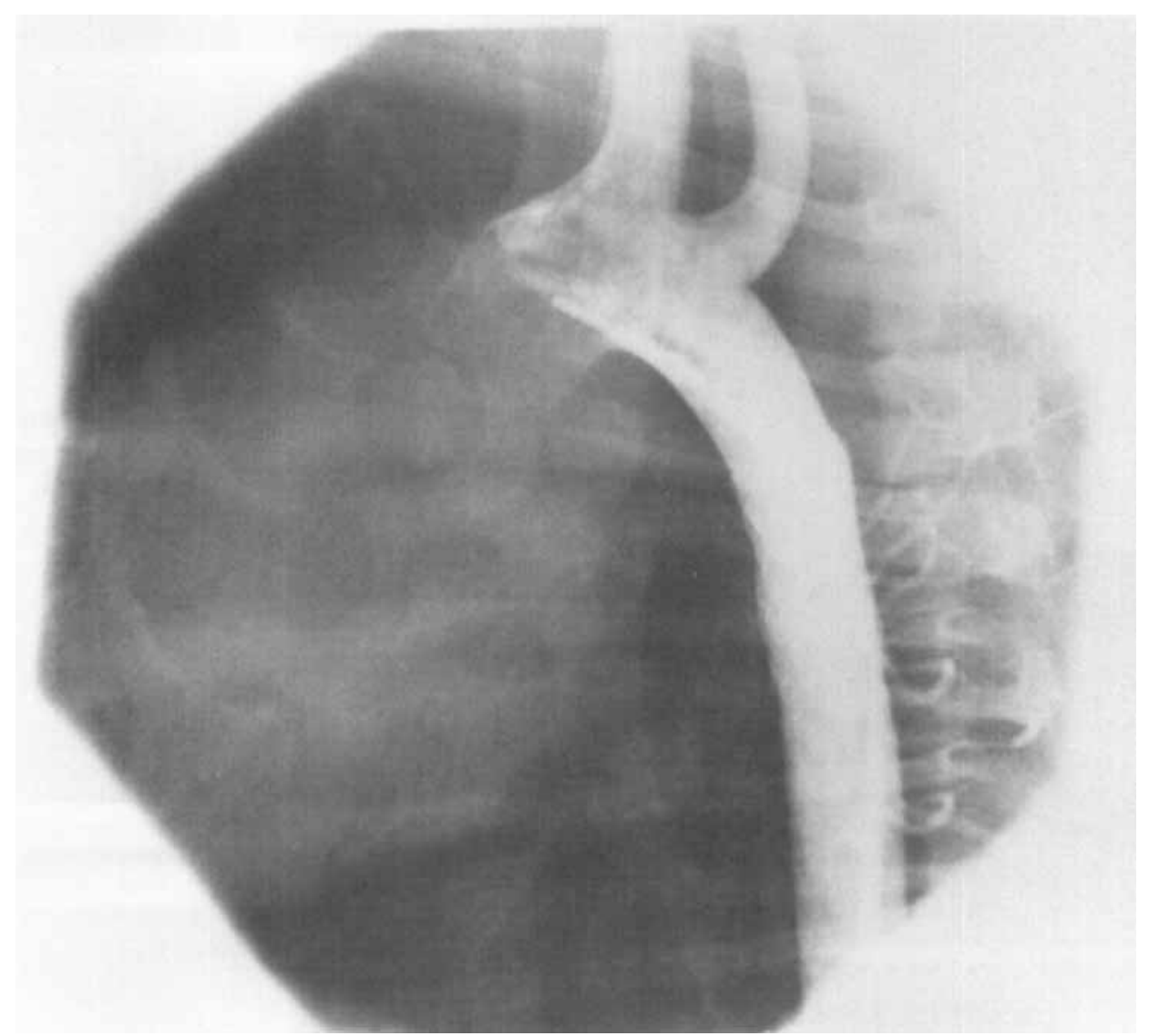

Figure 4. Aortogram (left anterior oblique projection) 6 weeks after coarctation stenting, demonstrating late patency of the intercostal arteries traversed by the stent.

Pathological Data. Gross examination found all stented aortic segments to be widely patent, without evidence of thrombosis or aneurysm formation. In the single specimen evaluated 4 weeks after stenting. a thin milky white neointima covered approximately $50 \%$ of the stent. The remaining five specimens were evaluated 6-7 weeks after stenting and the neointima coverage was virtually complete in all. Neointima was absent only on small portions of stents overlying arterial side branches. Patent orifices of the intercostal arteries arising from the stented aorta were evident in all specimens (Fig. 6).

Microscopic evaluation revealed that the neointima on each stent consisted of an endothelial cell surface. covering a layer of intimal proliferation (4-6 week specimens) or fibrosis (6-7 week specimens). Localized shallow areas of medial necrosis were found immediately beneath several stent wires (Fig. 7). Small patches of medial calcification were noted in two specimens, and a larger medial calcification noted in one. Arterial side branches arising from the stented aortic segments were patent (Fig. 8).

\section{Discussion}

Coarctation of the aorta affects approximately $8 \%-10 \%$ of children with congenital heart disease. The goal of therapy is to relieve the hemodynamic and anatomical stenosis, without early or late restenosis and without aneurysm formation at the site of repair. Current methods of treatment have had mixed results. Residual or recurrent stenosis, as well as late aneurysm formation, have been well-described following either surgery 

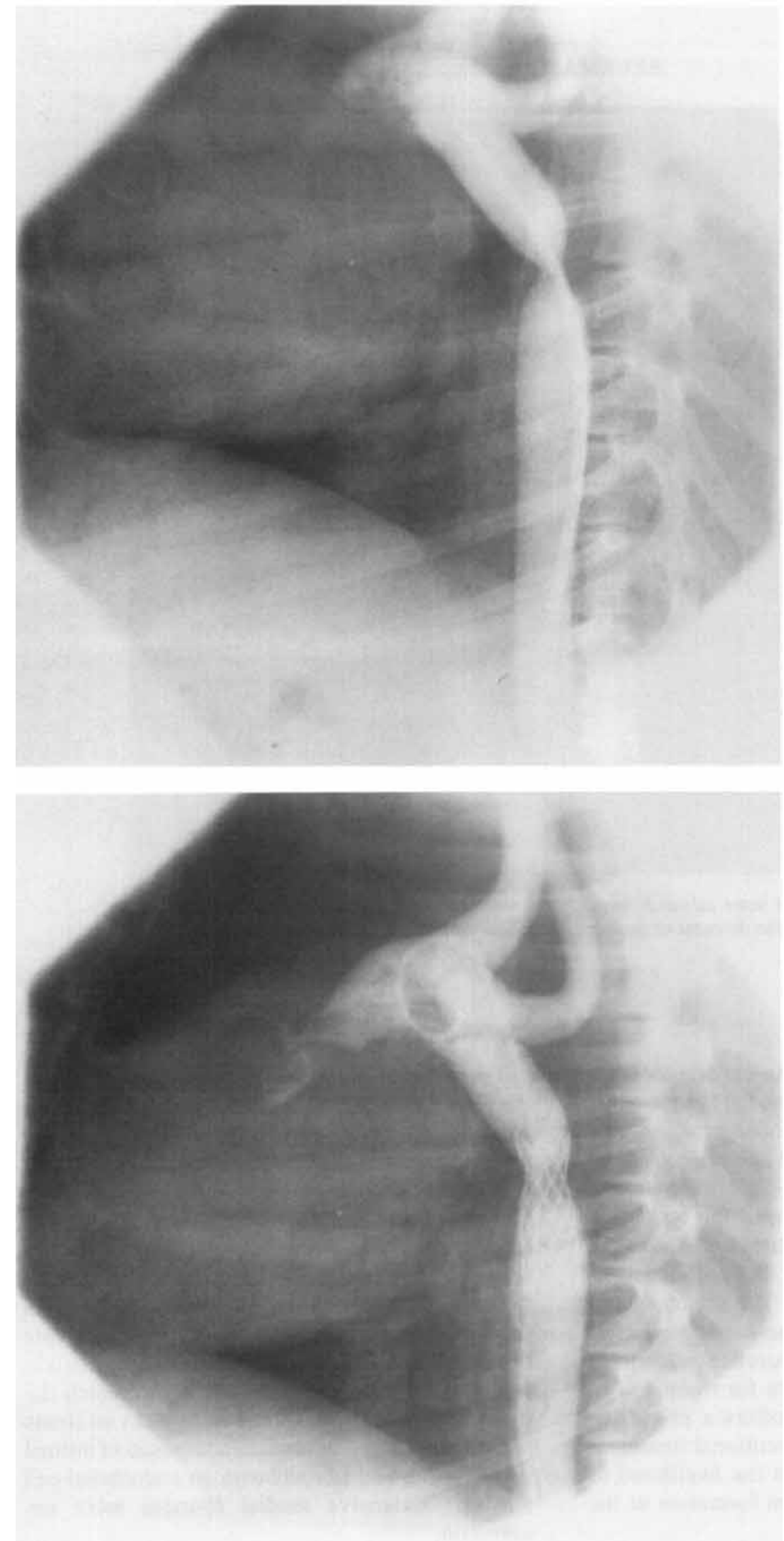

Figure 5a. Aortogram (left anterior oblique projection) showing a discrete coarctation in a $10.9-\mathrm{kg}$ puppy. The pressure gradient was $42 \mathrm{mmHg}$.

Figure 5b. Immediately after stenting, the stent is noted to be poorly centered on the coarctation with a distal diameter substantially smaller than the diameter of the poststenotic aorta. 


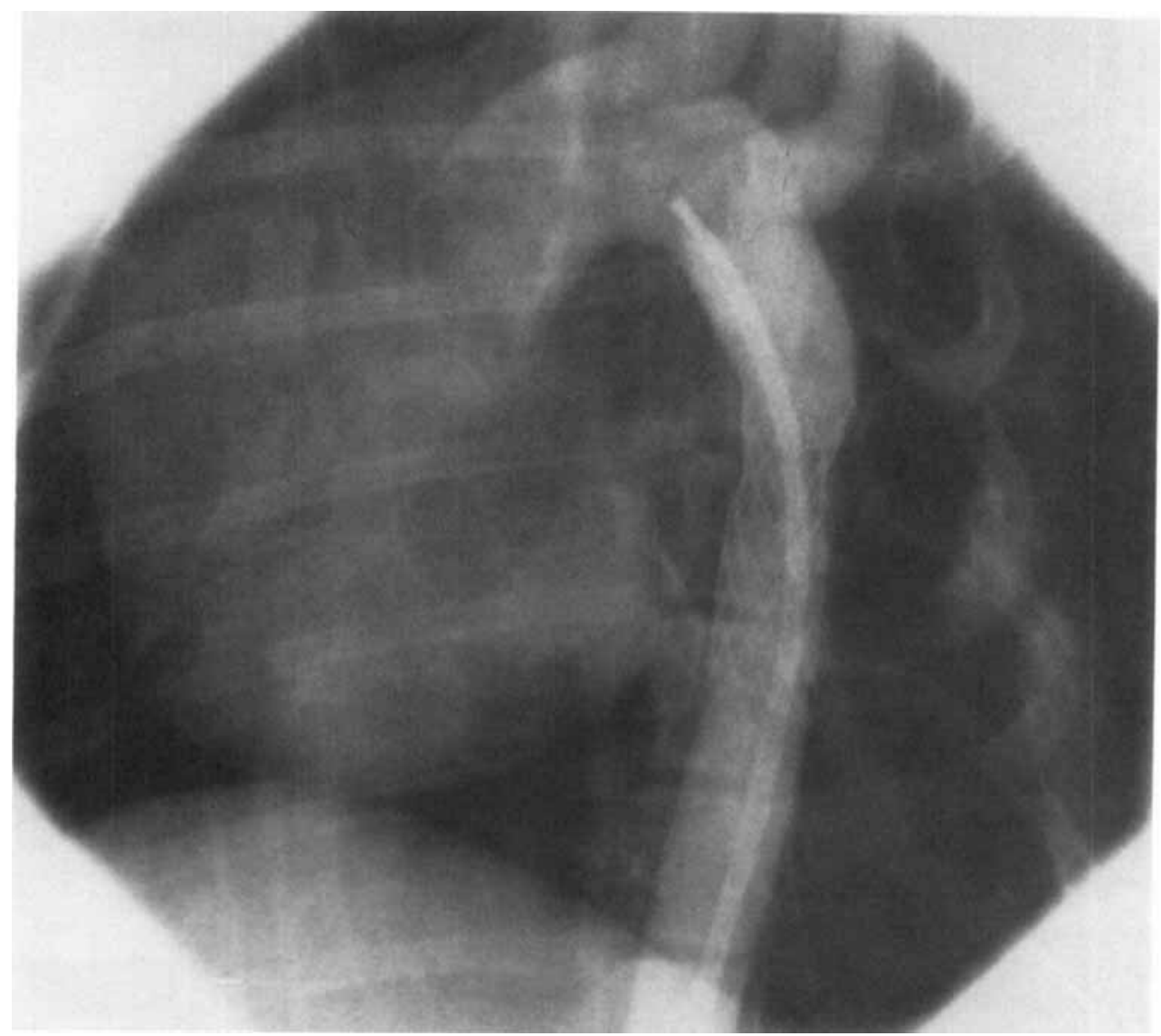

Figure 5c. Aortogram of same animal 6 weeks later, demonstrating that the poststenotic aorta had remodeled to now equal the diameter of the stent. There was no residual gradient or evidence of thrombosis.

or balloon angioplasty. ${ }^{1-10}$ The experience with angioplasty, however, has provided the rationale for attempting stent treatment of coarctation. Angioplasty alone fails to provide adequate gradient relief in approximately $20 \%-25 \%$ of patients, often due to the elastic nature of the lesion. In many patients the coarctation tissue dilates as the angioplasty balloon is inflated, but recoils immediately upon balloon deflation. The use of a stainless steel stent, to buttress the aortic wall after dilation, therefore holds a theoretical advantage over naked balloon angioplasty for treatment of coarctation. Stent treatment offers a promising nonsurgical alternative to conventional treatment strategies which may diminish the likelihood of residual stenosis and aneurysm formation at the site of coarctation repair.
The current investigation has provided preliminary data confirming the potential effectiveness of stent treatment for coarctation of the aorta. In an experimental coarctation model, the Palmaz balloon-expandable stainless steel stent has been shown to provide acute hemodynamic and angiographic relief of coarctation stenosis. Short-term follow-up evaluation (4-7 weeks) found no evidence of early restenosis, thrombosis, aneurysm formation, or obstruction to arterial side branches. In two dogs, the poststenotic aorta was found to undergo early remodeling to match the diameter of the stent. Within 6-7 weeks all stents were covered by a neointima composed of intimal proliferation and fibrosis with an endothelial cell surface. Extensive medial changes were uncommon. 


\section{STENT TREATMENT OF COARCTATION}

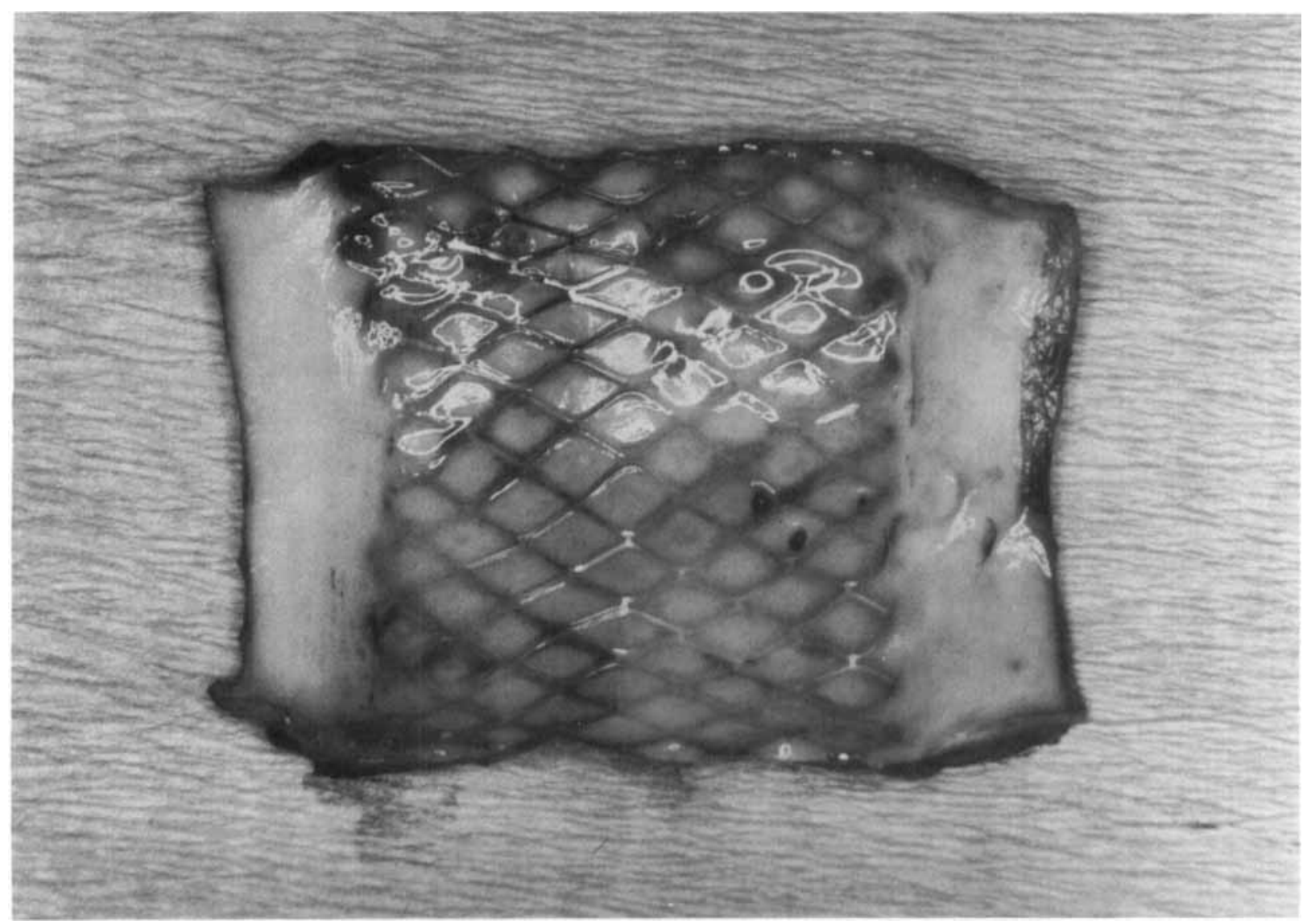

Figure 6. Gross specimen 7 weeks after coarctation stenting. Neointimal coverage is nearly complete, with no evidence of thrombosis or aneurysm. The patent orifices of several intercostal arteries are evident.

Previous Studies of Arterial Stenting. Balloonexpandable stent treatment of systemic arterial stenoses has been evaluated previously in animal and human studies. ${ }^{1-16}$ The Palmaz stainless steel stent was developed specifically to provide transcatheter relief of vascular stenoses, and its effects have been extensively evaluated including after placement in the aortic position. For example, Palmaz and colleagues evaluated the stent in the aortas of 24 atherosclerotic rabbits. ${ }^{12}$ Pathological evaluation 1-24 weeks after stent placement documented persistent patency without stenosis. Subsequently, clinical trials have evaluated stents in patients with coronary or peripheral artery stenosis, ${ }^{14,15}$ as well as in children with pulmonary artery stenosis. ${ }^{17}$ Although late restenosis has been documented in some coronary arteries, restenosis occurs less commonly when stents are placed in larger arteries such as the iliac or pulmonary arteries. There are very few data regarding the use of stents to treat coarctation of the aorta, however. In an abstract, Morrow and colleagues presented their experience using balloon-expandable stents to treat an experimental coarctation in seven swine. ${ }^{18}$ Stenting decreased the systolic coarctation gradient from 26 $\mathrm{mmHg}$ to $1 \mathrm{mmHg}$, but histologic data were not reported. Finally, O'Laughlin et al. have reported one patient with coarctation in whom a stent was implanted after unsuccessful balloon angioplasty. ${ }^{17}$

Limitations of the Present Study. Several limitations of the present study must be acknowledged. First, the small number of animals limits the investigation's power to detect a significant incidence of restenosis or aneurysm formation. Lim- 
BEEKMAN, ET AL.

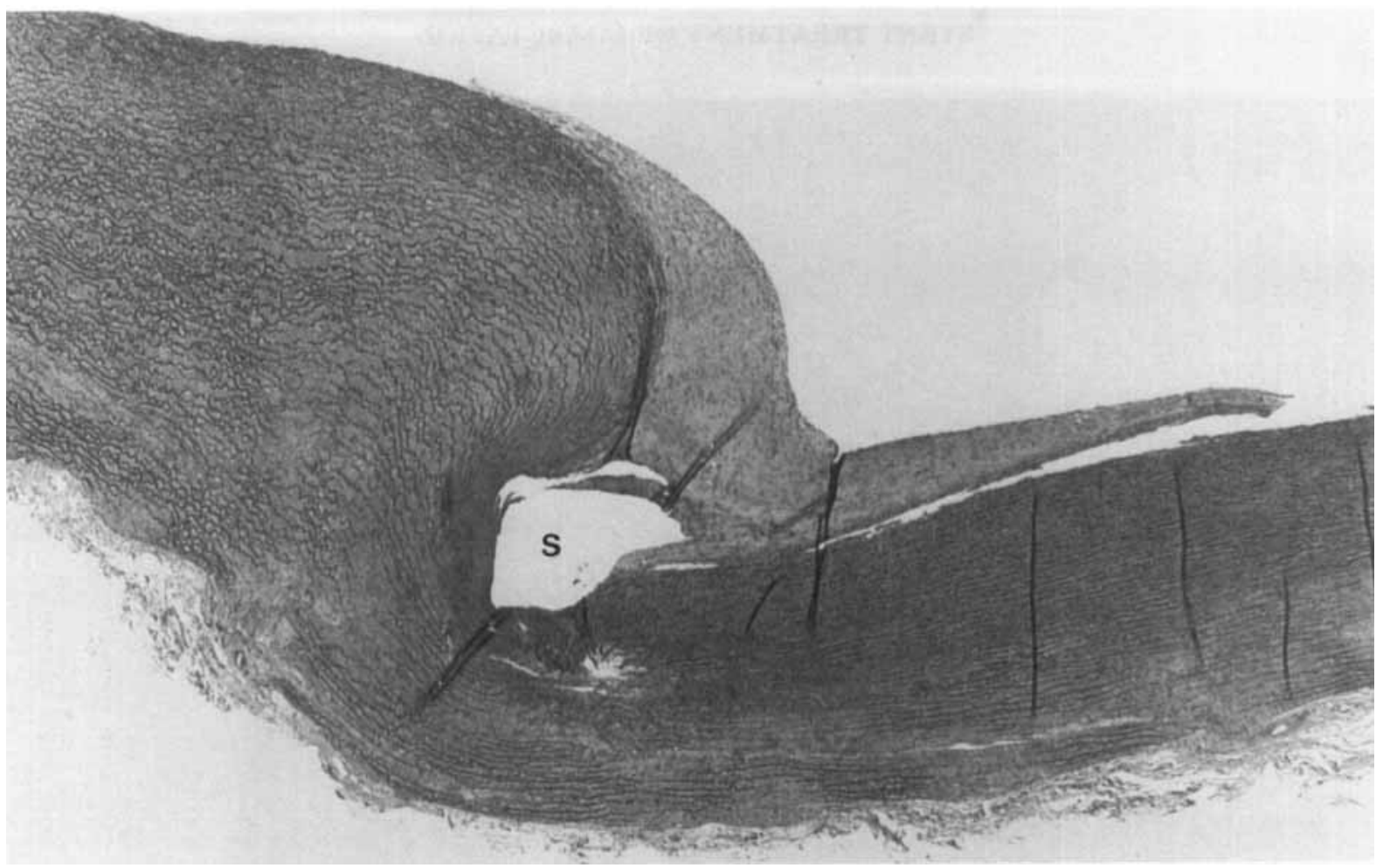

Figure 7. Section of stented aorta showing site of stent wire (S) with underlying focal medial necrosis and hemosiderin pigment. The "neointima" above the stent consists of intimal proliferation and fibrosis with a surface endothelium. ( $\mathrm{H}$ and $\mathrm{E} \times 63$.)

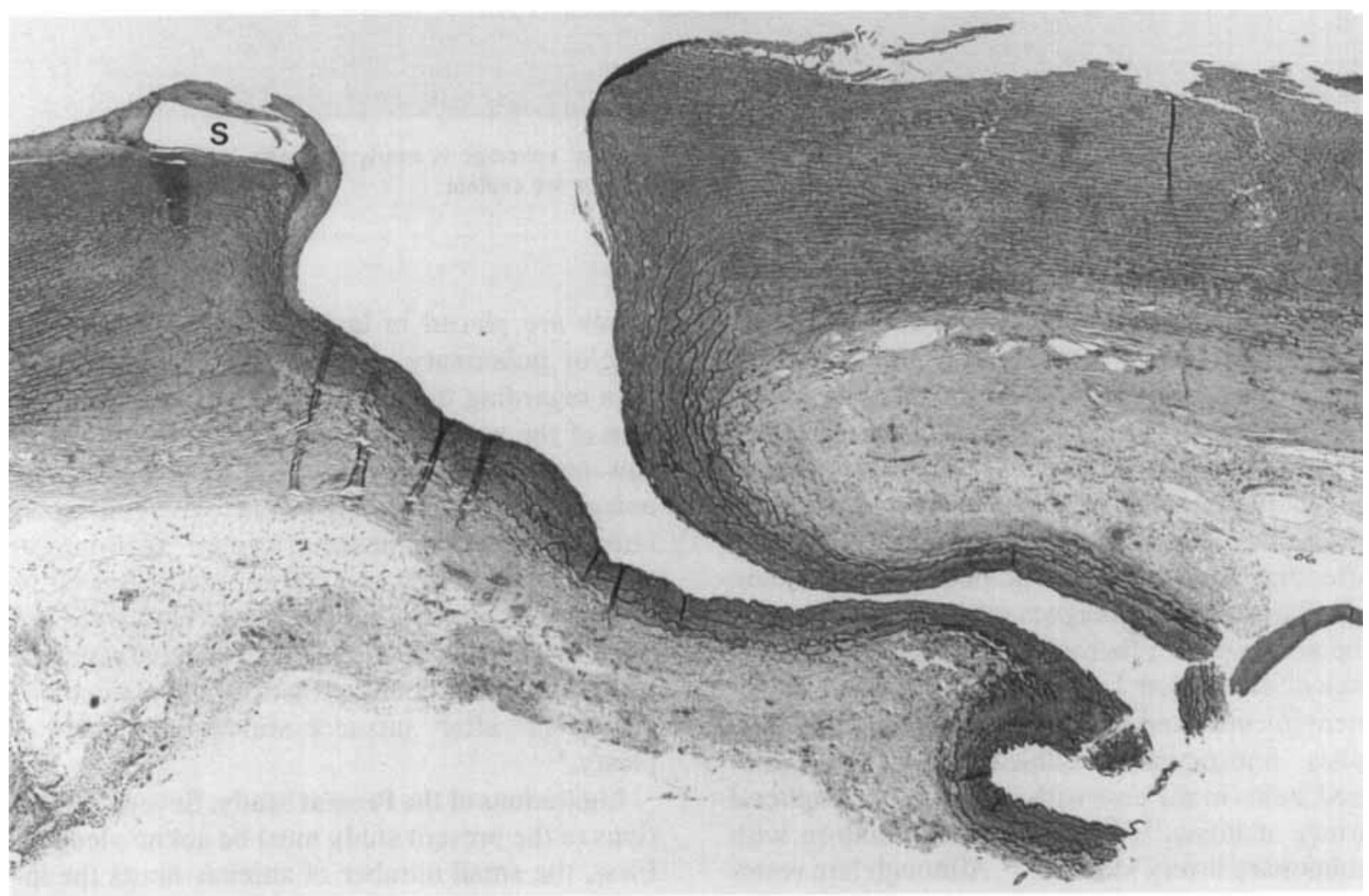

Figure 8. The origin of a patent intercostal artery is seen arising adjacent to (and between) stent wire (S) sites. (H and $E \times 29$. 
ited statistical power also explains our inability to detect a significant change in ascending aorta pressure after stenting. Second, the 4-7 week follow-up duration is short. Previous studies of coronary artery stents have suggested that neointimal proliferation has not reached its maximum level until approximately 3-6 months after stenting. ${ }^{16}$ Third, this study does not provide data regarding patency of the left subclavian artery if a stent covers it's origin since, in all animals, the stent was positioned distal to the subclavian artery. Previous studies have shown that large coronary artery and pulmonary artery side branches remain patent when crossed by a stent, ${ }^{14,15,17}$ and we therefore speculate that flow to the left subclavian artery will not be compromised if a stent crosses it's origin. Finally, the experimental model of coarctation evaluated in this study may not relate well to native (unoperated) human coarctation. It may be more representative of postoperative recurrent coarctation (i.e., after prior surgical repair). Since an animal model of native coarctation is not available, it remains to be determined if balloon-expandable stents can be used to effectively treat native lesions. The experience that many native coarctations dilate during balloon angioplasty only to recoil upon balloon deflation, however, suggests that stents may succeed in treating native coarctations as well.

\section{Conclusions}

The current investigation has provided preliminary data indicating that balloon-expandable stents can be used successfully to treat an experimental model of coarctation of the aorta. In six animals, the Palmaz stainless steel stent provided effective relief of hemodynamic and angiographic stenosis without early restenosis, thrombosis, or aneurysm formation. Additional studies are necessary, with a larger number of animals and a longer follow-up duration, to better determine the risks of restenosis or aneurysm formation following coarctation stenting. Further, since human coarctation is best treated in childhood, studies are needed to determine if a stent implanted to treat coarctation in a growing animal can be safely redilated to a larger diameter after the animal has grown.

\section{References}

1. Beekman RH, Rocchini AP, Behrendt D, et al. Reoperation for coarctation of the aorta. Am J Cardiol 1981; 48: 1108-1114.

2. Beekman RH, Rocchini AP, Behrendt DM, et al. Longterm outcome after repair of coarctation in infancy: Subclavian angioplasty does not reduce the need for reoperation. J Am Coll Cardiol 1986; 8:1406-1411.

3. Patel R, Singh SP. Abrams L, et al. Coarctation of aorta with special reference to infants. Long-term results of operation in 126 cases. Br Heart J 1977; 39:1246-1253.

4. Messmer BJ, Minale C, Muhler E, et al. Surgical correction of coarctation in early infancy: Does surgical technique influence the result? Ann Thorac Surg 1991; 52: 594-603.

5. Bromberg BI, Beekman RH, Rocchini AP, et al. Aortic aneurysm following patch aortoplasty repair of coarctation: A prospective analysis of prevalence screening tests and risks. J Am Coll Cardiol 1989; 14:734-741.

6. Del Nido PJ, Williams WG, Wilson GJ, etal. Synthetic patch angioplasty for repair of coarctation of the aorta: Experience with aneurysm formation. Circulation 1986; 74(Suppl. 1):I-32-I-36.

7. Beekman RH, Rocchini AP, Dick M, etal. Percutaneous balloon angioplasty for native coarctation of the aorta. J Am Coll Cardiol 1987; 10:1078-1084.

8. Morrow WR, Vick GW, Nihill MR, etal. Balloon dilation of unoperated coarctation of the aorta: Short and intermediate-term results. J Am Coll Cardiol 1988; 11: $133-138$.

9. Saul JP. Keane JF, Fellows KE, et al. Balloon dilation angioplasty of postoperative aortic obstructions. Am J Cardiol 1987; 59:943-948.

10. Lababidi ZA, Daskalopoulos DA, Stoeckel H. Transluminal balloon coarctation angioplasty: Experience with 27 patients. Am J Cardiol 1984; 54:1288-1291.

11. Trent MS, Parsonnet V, Shoenfeld R, et al. A balloonexpandable intravascular stent for obliterating experimental aortic dissection. J Vasc Surg 1990; 11:707-717.

12. Palmaz JC, Sibbitt RR, Tio FO, et al. Expandable intraluminal vascular graft: A feasibility study. Surgery 1986; 99: 199-205

13. Schatz RA, Palmaz JC, Tio FO, et al. Balloon-expandable intracoronary stents in the adult dog. Circulation 1987; 76:450-457.

14. Sigwart U, Puel J, Mirkovitch V, et al. Intravascular stents to prevent occlusion and restenosis after transiuminal angioplasty. N Engl J Med 1987; 316:701-706.

15. Palmaz JC. Garcia 0, Schatz RA, et al. Placement of balloon-expandable intraluminal stents in iliac arteries: First 171 procedures. Radiology 1990; 174:969-975.

16. Robinson KA, Roubin G, King S, et al. Correlated microscopic observations of arterial responses to intravascular stenting. Scan Microscopy 1989; 3:665-679.

17. O'Laughlin MP, Perry SB, Lock JE, et al. Use of endovascular stents in congenital heart disease. Circulation 1991; 83:1923-1939.

18. Morrow WR, Smith VC, Ehler WJ. et al. Balloon-expandable endovascular stents in experimental coarctation of the aorta. (abstract) Circulation 1989; 80(4):II593. 